\title{
PPAR $\gamma$ isoforms differentially regulate metabolic networks to mediate mouse prostatic epithelial differentiation
}

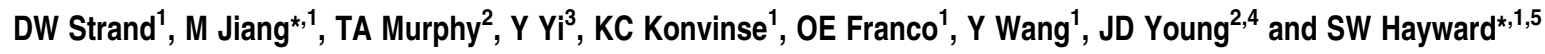

Recent observations indicate prostatic diseases are comorbidities of systemic metabolic dysfunction. These discoveries revealed fundamental questions regarding the nature of prostate metabolism. We previously showed that prostate-specific ablation of PPAR $\gamma$ in mice resulted in tumorigenesis and active autophagy. Here, we demonstrate control of overlapping and distinct aspects of prostate epithelial metabolism by ectopic expression of individual PPAR $\gamma$ isoforms in PPAR knockout prostate epithelial cells. Expression and activation of either PPAR $\gamma 1$ or 2 reduced de novo lipogenesis and oxidative stress and mediated a switch from glucose to fatty acid oxidation through regulation of genes including Pdk4, Fabp4, Lpl, Acot1 and Cd36. Differential effects of PPAR $\gamma$ isoforms included decreased basal cell differentiation, Scd1 expression and triglyceride fatty acid desaturation and increased tumorigenicity by PPAR $\gamma 1$. In contrast, PPAR $\gamma 2$ expression significantly increased basal cell differentiation, Scd1 expression and AR expression and responsiveness. Finally, in confirmation of in vitro data, a PPAR $\gamma$ agonist versus high-fat diet (HFD) regimen in vivo confirmed that PPAR $\gamma$ agonization increased prostatic differentiation markers, whereas HFD downregulated PPAR $\gamma$-regulated genes and decreased prostate differentiation. These data provide a rationale for pursuing a fundamental metabolic understanding of changes to glucose and fatty acid metabolism in benign and malignant prostatic diseases associated with systemic metabolic stress.

Cell Death and Disease (2012) 3, e361; doi:10.1038/cddis.2012.99; published online 9 August 2012

Subject Category: Cancer Metabolism

Benign prostatic hyperplasia (BPH) and prostate cancer (PCa) are age-related diseases associated with complications of metabolic syndrome (MetS). ${ }^{1}$ However, the molecular underpinnings of prostatic susceptibility to systemic metabolic dysfunction are poorly understood, in part because dietary and transgenic animal models display a limited recapitulation of human benign growth and stromal expansion or adenocarcinoma. Furthermore, unlike adipose, muscle and liver, understanding of the effects of systemic metabolic stressors on prostate growth and/or transformation are hampered by a limited understanding of the prostate's normal nutritional metabolism.
Epidemiological links between BPH and diabetes have been recognized for many years ${ }^{2}$ and recent studies have demonstrated that the incidence and severity of $\mathrm{BPH}$ are correlated with obesity, atherosclerosis, diabetes mellitus, hyperinsulinemia, hyperglycemia and hypercholesterolemia. ${ }^{3,4,5,6,7}$ Although diabetes mellitus has a negative correlation with the incidence of multiple cancers including prostate, diabetic patients exhibit increased mortality. ${ }^{8}$ Moreover, MetS as a set of comorbidities (obesity, insulin resistance, dyslipidemia and hypertension) is correlated with $\mathrm{PCa}$ incidence. ${ }^{9}$ Such associations have prompted the

\footnotetext{
${ }^{1}$ Department of Urologic Surgery, A-1302 MCN, Vanderbilt-Ingram Comprehensive Cancer Center, Vanderbilt University School of Engineering, and Vanderbilt University Medical Center, Nashville, TN 37232-2765, USA; ${ }^{2}$ Department of Chemical and Biomolecular Engineering, Vanderbilt-Ingram Comprehensive Cancer Center, Vanderbilt University School of Engineering, and Vanderbilt University Medical Center, Nashville, TN 37232-2765, USA; ${ }^{3}$ Department of Medicine and Institute for Integrative Genomics, Vanderbilt-Ingram Comprehensive Cancer Center, Vanderbilt University School of Engineering, and Vanderbilt University Medical Center, Nashville, TN 37232-2765, USA; ${ }^{4}$ Department of Molecular Physiology and Biophysics, Vanderbilt-Ingram Comprehensive Cancer Center, Vanderbilt University School of Engineering, and Vanderbilt University Medical Center, Nashville, TN 37232-2765, USA and ${ }^{5}$ Department of Cancer Biology, Vanderbilt-Ingram Comprehensive Cancer Center, Vanderbilt University School of Engineering, and Vanderbilt University Medical Center, Nashville, TN 37232-2765, USA

*Corresponding authors: M Jiang, Department of Urologic Surgery, A-1302 MCN, Vanderbilt University Medical Center, Nashville, TN 37232-2765, USA. Tel: 615343 5984; Fax: 615322 8990; E-mail: ming.jiang.1@ vanderbilt.edu

or SW Hayward, Department of Urologic Surgery, A-1302 MCN, Vanderbilt University Medical Center, Nashville, TN 37232-2765. Tel: 615 343 5823; Fax: 615343 8990; E-mail: simon.hayward@vanderbilt.edu

Keywords: prostate; differentiation; peroxisome proliferator-activated receptor gamma $(\gamma)$; PPAR $\gamma$; fatty acid metabolism; androgen receptor

Abbreviations: acetyl-COA, acetyl coenzyme A; AR, androgen receptor; ARE, androgen response element; $B P H$, benign prostatic hyperplasia; DHT, dihydrotestosterone; eWAT, epididymal white adipose tissue; HFD, high-fat diet; MetS, metabolic syndrome; mPrE-PPAR $\mathrm{KO}$ (mPrE- $\gamma \mathrm{KO}$ ), a PPAR $\gamma$ knockout

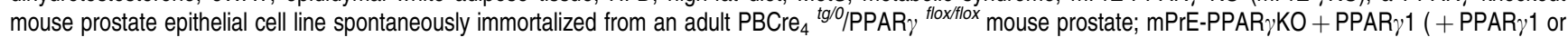
$+\gamma 1$ ), mPrE- $\gamma$ KO overexpressing mouse PPAR $\gamma 1$ WT full-length CDNA; mPrE-PPAR $\gamma$ KO + PPAR 22 (+ PPAR $\gamma 2$ or $+\gamma 2$ ), mPrE- $\gamma$ KO overexpressing mouse PPAR $\gamma 2$ WT full-length cDNA; mPrE-PPAR $\gamma \mathrm{KO}+$ empty vector $(+\mathrm{EV}), \mathrm{mPrE}-\gamma \mathrm{KO}$ retrovirally transduced using a control empty vector; MUFAs, monounsaturated fatty acids; KO, knockout; PCa, prostate cancer or prostate carcinoma; PIN, prostatic intraepithelial neoplasia; PPAR $\gamma$, peroxisome proliferator-activated receptor gamma; ROS, reactive oxygen species; TCA, tricarboxylic acid; TZDs, thiazolidinediones; UGM, urogenital mesenchyme

Received 09.5.12; revised 06.6.12; accepted 21.6.12; Edited by C Munoz-Pinedo
} 
investigation of metabolic genes and potential metabolic therapies in benign and malignant prostatic diseases. ${ }^{3,10}$

The peroxisome proliferator-activated receptors (PPARs) are a family of nuclear fatty acid receptors that regulate tissuespecific cellular metabolism and differentiation and have been widely sought after therapeutic targets for a number of obesity-related metabolic diseases owing to their ability to regulate glucose and fatty acid metabolism. ${ }^{11,12} \mathrm{~A}$ class of PPARgamma (PPAR $\gamma$ ) agonists called thiazolidinediones (TZDs) are used in the treatment of insulin resistance and regulate a wide range of genes with tissue-specific effects. ${ }^{13}$

Historically, PPAR $\gamma$ has been associated with pre-adipocyte expansion and differentiation, ${ }^{14}$ but other tissues also show a functional role for PPAR $\gamma$, including $\operatorname{liver}^{15}$ and muscle. ${ }^{16}$ We showed previously that PPAR $\gamma$ ablation in mouse prostate causes tumorigenesis and active autophagy, ${ }^{17,18}$ suggesting PPAR $\gamma$ may provide a molecular link between systemic metabolism and prostate differentiation and growth. ${ }^{19}$ There are two isoforms of PPAR $\gamma$ with the longer PPAR $\gamma 2$ isoform using an alternate transcription start site containing a 30 -amino acid $\mathrm{N}$-terminal extension.

Our goal in this study was to garner a fundamental molecular and cellular understanding of the role of PPAR $\gamma$ in mediating metabolic control of prostatic differentiation. Because of the importance of individual PPAR $\gamma$ isoforms in systemic metabolism and our previous work implicating PPAR $\gamma$ in prostate epithelial growth and differentiation, we chose to examine the potential roles of individual PPAR $\gamma$ isoforms in mediating nutrient metabolism in the prostate, which has not been performed in any tissue. A prostatic epithelial cell line (mPrE-PPAR $\gamma \mathrm{KO}$ ) restored with either PPAR $\gamma 1$ or PPAR $\gamma 2$ isoform was used to determine how each isoform might contribute to prostatic metabolism, differentiation and disease. We show, using in vitro analysis, lipidomics and in vivo animal models that PPAR $\gamma$ isoforms control overlapping and distinct metabolic programs in prostate epithelia that lead to functional changes in glucose and lipid metabolism and that these changes are coordinate with reduced lipogenesis, increased $\beta$-oxidation and markers of basal and luminal epithelial differentiation. Furthermore, we show in animals that prostate differentiation is oppositely affected after chronic treatment with a TZD versus high-fat diet (HFD) through disparate regulation of PPAR $\gamma$-and its downstream genes. These data suggest, as in other tissues, that PPAR $\gamma$ agonization may directly or indirectly modulate the nutritional supply of glucose and lipids for prostate metabolism and differentiation.

\section{Results}

Restoration of PPAR 2 , but not PPAR $\gamma 1$, reverses PPAR $\gamma$ KO-induced mouse prostatic carcinogenesis. Alternative transcription start sites and splicing produce two PPAR $\gamma$ isoforms, so only the longer PPAR $\gamma 2$ isoform can be knocked out individually. ${ }^{20}$ In order to study the independent functions of PPAR $\gamma 1$ and $-\gamma 2$ isoforms on prostate metabolism and differentiation, we developed a prostate epithelial cell line (mPrE-PPAR $\gamma \mathrm{KO}$ ) with genetic knockout $(\mathrm{KO})$ of both PPAR $\gamma 1$ and $-\gamma 2$ isoforms from an adult PB-Cre4 $\mathrm{tg} / 0$ / PPAR $\gamma^{\text {flox/flox }}$ double-transgenic male mouse. ${ }^{17}$ We then restored $\mathrm{mPrE}-\gamma \mathrm{KO}$ cells with mouse PPAR $\gamma 1$ cDNA ( + PPAR $\gamma 1$ ), PPAR 2 cDNA ( + PPAR $\gamma 2$ ) or an empty vector $(+E V)$ as control, respectively, to create an isogenic series of cell lines for genetic and functional comparisons (see Materials and Methods).

In order to determine the effects of PPAR $\gamma$ isoforms on tissue morphogenesis in vivo, $\mathrm{mPrE}-\gamma \mathrm{KO}$ and restored cell lines were each recombined with inductive 18-day fetal rat urogenital mesenchyme (UGM) and grafted into the kidney capsule for 2 months (Figures 1a-c). Control mPrE- $\gamma \mathrm{KO}+\mathrm{EV}$ cells (empty vector-transfected) regenerated highgrade mouse prostatic intraepithelial neoplasia (HGPIN) (Jiang et al. ${ }^{17}$; Figure 1a) with predominantly $\mathrm{Ck} 8 / \mathrm{Ck} 18^{+}$ luminal epithelial glands and few $\mathrm{Ck}_{14}{ }^{+}$basal cells (Figure 1d). Upon restoration with PPAR 1 , large areas of Ck8/18 ${ }^{++} / \mathrm{Ck}_{14}{ }^{-}$middle or highly differentiated adenocarcinoma were observed in + PPAR $\gamma 1$ tissue recombinants (Figure 1b, black star, Figure 1e), but large fluid-filled cysts were also formed (Figure $1 \mathrm{~b}$, white star). PPAR $\gamma 2$ restoration resulted in the regeneration of $\mathrm{Ck} 8 / 18^{+} / \mathrm{Ck} 14^{++}$acini that resembled developing prostate glands without evidence of tumor formation (Figures 1c and f). Furthermore, androgen receptor $(A R)$ expression was demonstrated in regenerated tissues by immunohistochemical staining using $+\mathrm{EV}$ or + PPAR $\gamma 2$ cells, but not with + PPAR $\gamma 1$ cells (Figures 1g-i). These data indicate that restoration of PPAR $\gamma 2$ isoform, but not PPAR $\gamma 1$ isoform, reverses PPAR $\gamma$-deficient mouse prostatic carcinogenesis through an increase in $\mathrm{Ck}_{14}{ }^{+}$basal cells.

PPAR $\gamma$ isoforms 1 and 2 differentially regulate mouse prostate benign epithelial cell differentiation as well as luminal AR expression and function. In order to confirm the in vivo restoration of basal and luminal differentiation by PPAR $\gamma 2$ expression shown in Figure 1, protein expression in $\mathrm{mPrE}-\gamma \mathrm{KO}+\mathrm{EV}$, + PPAR $\gamma 1$ and + PPAR $\gamma 2$ cells was examined by western blot, which revealed increases in both Ck14 and AR upon expression of PPAR $\gamma 2$ (Figure 2a). To determine whether PPAR $\gamma$ isoform expression increased the differentiation of basal cells in vitro, each $\mathrm{mPrE}-\gamma \mathrm{KO}$ cell line was double stained in culture for PPAR $\gamma$ and Ck14 (Figure 2b(i-iii)). Results demonstrated that although PPAR $\gamma$ expression in + PPAR $\gamma 1$ cells was increased $14 \%$ versus $+\mathrm{EV}$ cells, this resulted in an insignificant change in Ck14 expression (Figure 2b (ii versus iii)). Alternatively, and consistent with regeneration experiments in vivo (Figure 1f), PPAR $\gamma 2$ restoration resulted in a $15 \%$ increase in PPAR $\gamma^{+}$cells as well as a $15 \%$ increase in $\mathrm{Ck}_{14}{ }^{+}$cells (Figure $2 \mathrm{~b}$ (iii), quantified in Figure $2 \mathrm{c}$ ). Interestingly, only 6$9 \%$ of the PPAR $\gamma^{+}$cells had overlapping Ck14 expression, suggesting a potential paracrine regulation of basal cell differentiation. To determine whether the increase in basal cells also resulted in increase luminal differentiation, cells were treated with dihydrotestosterone (DHT) and co-stained for AR and CK14 (Figure 2b(iv-vi)). In PPAR 2 2-rescued cells, cells adjacent to PPAR $\gamma^{+}$cells were observed to have nuclear AR localization (Figure 2b(vi), arrowhead). In contrast, fewer cells were found with nuclear AR localization in + EV or + PPAR $\gamma 1$ cells treated with DHT (Figure $2 b$ (iv versus $v$ )). To confirm increased $A R$ responsiveness, an androgen response element (ARE)-luciferase construct was 


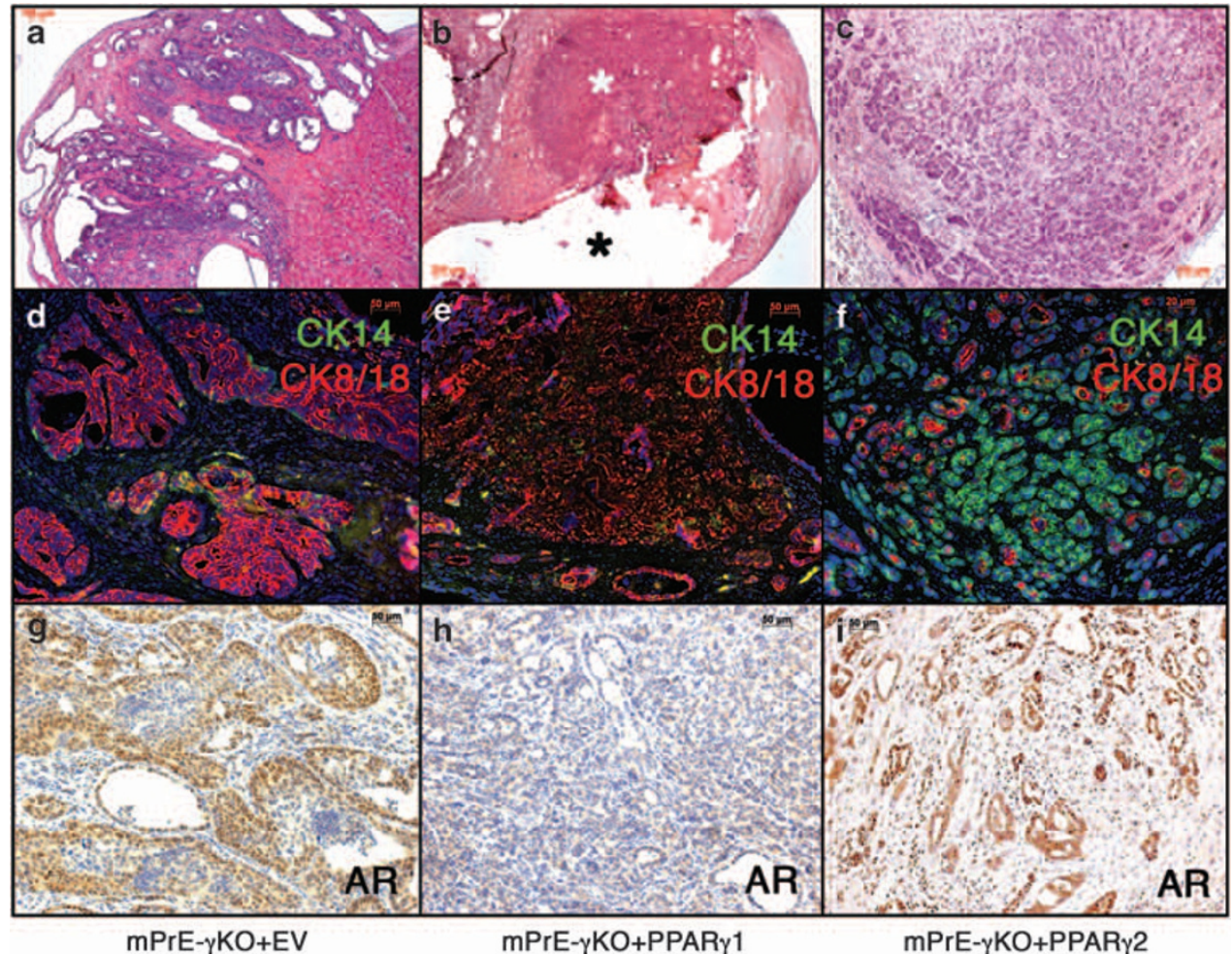

Figure 1 Restoration of PPAR $\gamma$ 2, but not PPAR $\gamma 1$, reverses PPAR $\gamma$ KO-induced mouse prostate carcinogenesis. mPrE-PPAR $\gamma \mathrm{KO}+\mathrm{EV},+\mathrm{PPAR} \gamma 1$ or $+\mathrm{PPAR} \gamma 2$ cell lines were recombined with inductive rat UGM and grafted under the kidney capsule for 2 months $\left(N=3\right.$ each). Histological analysis revealed regeneration of $\mathrm{Ck} 14^{+} / \mathrm{Ck} 18^{+} /$

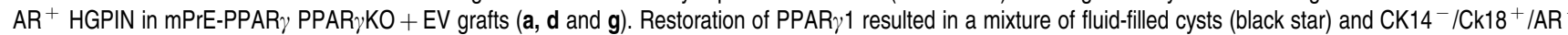
middle to highly differentiated adenocarcinoma (white star) $\left(\mathbf{b}, \mathbf{e}\right.$ and $\mathbf{h}$ ). Restoration of PPAR $\gamma 2$ resulted in regeneration of $\mathrm{Ck} 14^{++} / \mathrm{Ck}_{18}{ }^{+} / \mathrm{AR}^{+}$benign acinus formation without any tumors $(\mathbf{c}, \mathbf{f}$ and $\mathbf{i})$

transfected in each cell line, which demonstrated that + PPAR $\gamma 2$ cells significantly increased AR responsiveness 3-fold, while +PPAR $\gamma 1$ cells had no response and $\mathrm{mPrE}-\gamma \mathrm{KO}+\mathrm{EV}$ cells had a 1.8-fold increase (Figure $2 \mathrm{~d}$ ). The results showed restoration of PPAR $\gamma 2$ rescues and drives mouse prostate benign epithelial cell differentiation associated with AR activation.

PPAR $\gamma$ isoforms 1 and 2 regulate both overlapping and distinct metabolic networks. In order to determine the potential molecular disparity between PPAR $\gamma 1$ - and PPAR $\gamma 2-$ driven epithelial differentiation, microarrays were performed on mPrE-PPAR $\gamma \mathrm{KO}+\mathrm{EV}$ versus + PPAR 1 or + PPAR $\gamma 2$ cells. As outlined in Figure $3 a,+E V$ cells minus/plus Rosiglitazone (Rosi) were examined to eliminate PPAR $\gamma$ independent effects of Rosi (Supplementary Figure 1a). These independent effects were subtracted from results generated from comparison of + EV versus + PPAR $\gamma 1$ and + EV versus + PPAR $\gamma 2$ to identify PPAR $\gamma$-specific effects of Rosi. Using INGENUITY software (Redwood City, CA, USA) and the significance analysis of microarray (SAM) test for significance, Figure $3 b$ displays the top networks regulated by PPAR $\gamma$ isoforms in prostate epithelial cells. Individual genes regulated by PPAR $\gamma 1$ and PPAR $\gamma 2$ (top 10 up and down-regulated genes shown in Supplementary Figure 1a) included numerous focus molecules with functions related to amino acid, carbohydrate and lipid metabolism, drug metabolism and cellular detoxification as well as inflammation and immunity.

Restoration of PPAR 1 or $-\gamma 2$ isoforms reduces lipogenesis/oxidative stress. Microarray data analysis of PPAR $\gamma$ isoform-regulated genes showed a strong upregulation of genes involved in fatty acid metabolism, which has been shown to reduce de novo lipogenesis in some tissues; ${ }^{21}$ however, the influence of fatty acid metabolism on prostate differentiation has not been examined. Accordingly, western blotting revealed that PPAR 1 or PPAR $\gamma 2$ expression resulted in a decrease in lipogenic pathways (Akt, mTOR, Fasn, Acc) and oxidative stress (Cox-2) (Figure 4a). Flow cytometry of dihydroethidium-stained cell lines confirmed a significant reduction in reactive oxygen species (ROS) upon expression of PPAR $\gamma$ isoforms (Figure 4b). These data suggest that paracrine PPAR $\gamma$ expression satisfies the endogenous lipid needs, thereby negating the need for de novo lipogenesis.

To confirm candidate genes identified by INGENUITY software analysis, qRT-PCR plates were custom-designed for analysis of PPAR $\gamma$-restored cell lines. Results showed that both PPAR $\gamma$ isoforms regulated genes involved in metabolism (Table 1, Section I), including the modification (Elov/4, Scd1), transport (Cd36, Lpl, Fabp4) and $\beta$-oxidation (Acsf2, Lipa, Acot1) of fatty acids. In addition, multiple genes involved in detoxification were upregulated (Table 1, Section II), notably 
a

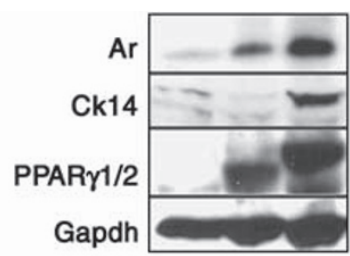

mPrE PPAR $\gamma K O+E V+\gamma 1+\gamma 2$
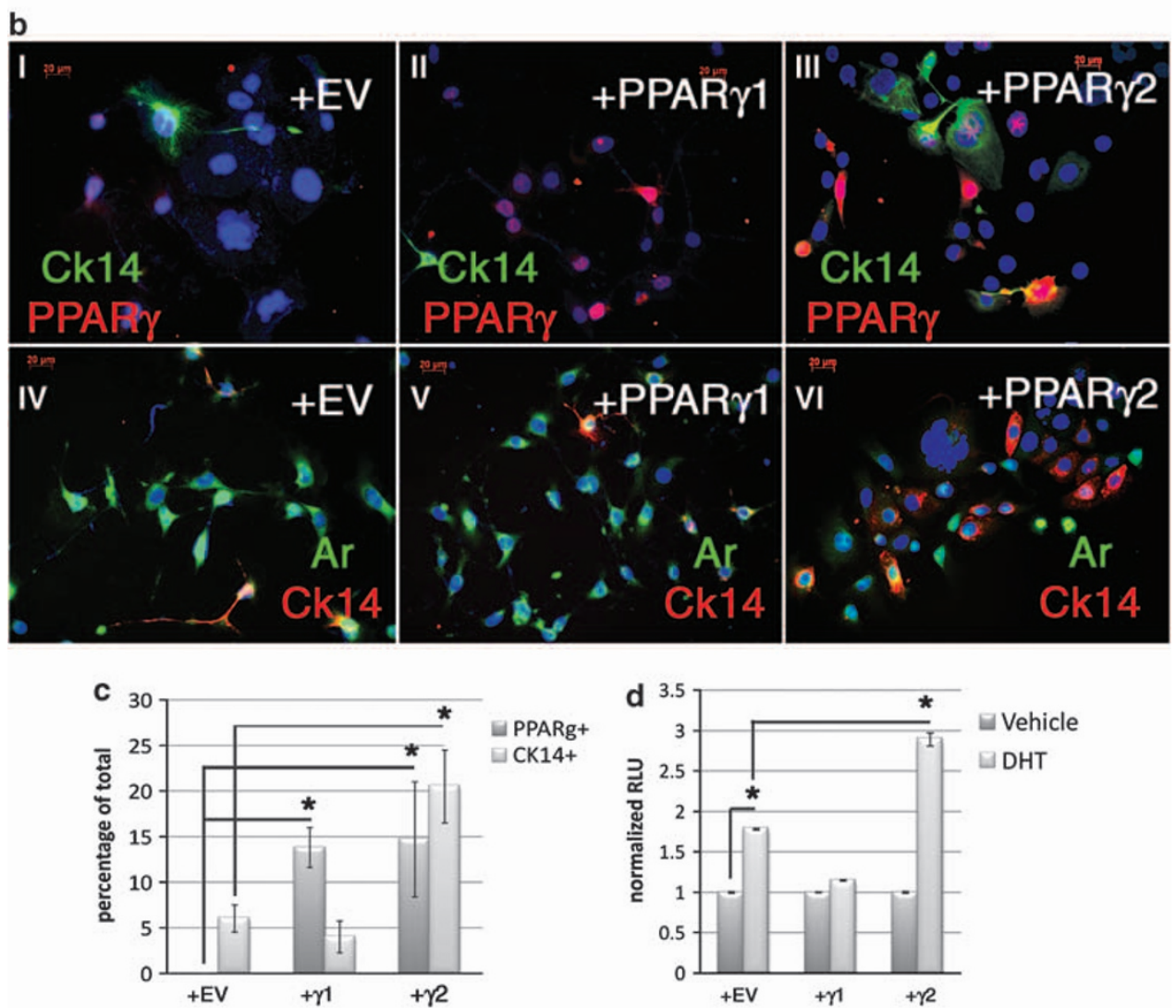

Figure 2 PPAR $\gamma$ isoforms 1 and 2 differentially regulate prostate basal differentiation as well as luminal AR expression and function. (a) Western blot analysis of $m$ PrE PPAR $\gamma K O$ + EV, + PPAR 1 or + PPAR 2 cells shows dual increase in Ck14 and AR in mPrE PPAR $\gamma K O+$ PPAR 2 cells compared with + EV or + PPAR 1 cells (b) ICC of PPAR $\gamma$ (red) and Ck14 (green) in mPrE-PPAR $\gamma K O+E V$ (i), + PPAR 1 (ii) or + PPAR 2 (iii) cells in culture shows an increase in Ck14 ${ }^{+}$cells in + PPAR 2 , but not + PPAR 1 cells. ICC for AR and Ck14 in mPrE-PPAR $\gamma$ KO + EV (iv), + PPAR 1 (v) or + PPAR 2 (vi) cells treated with DHT shows cytoplasmic AR in most mPrEPPAR $\gamma \mathrm{KO}+\mathrm{EV}$ or + PPAR $\gamma 1$ cells, whereas + PPAR $\gamma 2$ cells displayed increased nuclear AR immunoreactivity in cells adjacent to $\mathrm{Ck} 14^{+}$cells. (c) Quantitation of PPAR $\gamma$ immunoreactivity shows a significant increase of $15 \%$ for PPAR $\gamma$-restored cells compared with + EV cells, whereas only PPAR 2 -restored cells showed a significant $15 \%$ increase in Ck14 immunoreactivity compared with +EV cells. (d) Androgen responsiveness was increased three-fold in + PPAR 2 cells compared with + EV cells as measured by ARE-luciferase $(N=3)$. ${ }^{*} P$ value $<0.05$

including Cox-2, further confirming the decrease in ROS shown in Figure 4b. Finally, multiple markers of differentiation (Table 1, Section III) were upregulated, notably including regulation of basal cell (Trp63, Ck14) and luminal cell (Pbsn, $A R, P T E N$ ) markers by PPAR 2 , confirming the changes shown in Figure 1. These data suggest that increased fatty acid import results in a reduction in lipogenesis and oxidative stress.

PPAR isoforms differentially regulate glucose and fatty acid metabolism. One of the most interesting examples of isoform-specific changes in fatty acid modification genes was the differential regulation of $S c d 1$, which was upregulated by PPAR $\gamma 2$ but downregulated by PPAR $\gamma 1$ (Table 1, Section I).
Scd1 is an ER-resident fatty acid desaturase strongly induced by dietary saturated fat and responsible for the production of monounsaturated fatty acids (MUFAs) from 12 to 19 carbon saturated fatty acids, and has been implicated in numerous metabolic diseases. MUFAs are the preferred substrates in the synthesis of major lipid classes including phospholipids, cholesterol esters, wax esters and triglycerides. ${ }^{22,23}$

When various lipid classes were analyzed (phospholipids, diglycerides, triglycerides and cholesterol esters) in PPAR $\gamma 1$ and $-\gamma 2$-restored $\mathrm{mPrE}-\gamma \mathrm{KO}$ cells, we found that not only were total triglyceride stearic acid levels increased, but also that the PPAR 1-mediated Scd1 decrease resulted in a significantly increased abundance of stearic acid and decreased 


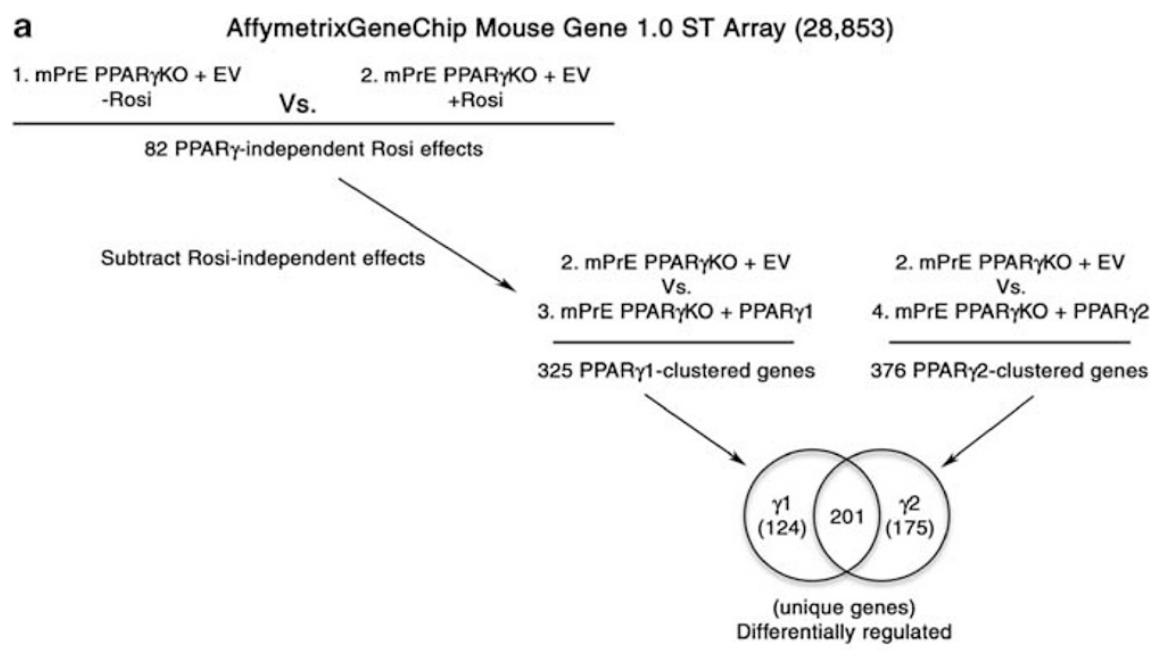

\begin{tabular}{|c|c|l|}
\hline b & PPARY1 & \multicolumn{2}{c|}{ PPARY2 } & \multicolumn{2}{l|}{ Top INGENUITY Networks } \\
\hline 22 & 24 & $\begin{array}{l}\text { Cellular Movement, Cell-To-Cell Signaling and Interaction, Cellular } \\
\text { Assembly and Organization }\end{array}$ \\
\hline 23 & 15 & Lipid Metabolism, Small Molecule Biochemistry, Cellular Development \\
\hline 22 & NA & Free Radical Scavenging, Molecular Transport \\
\hline 19 & 20 & $\begin{array}{l}\text { Antigen Presentation, Cellular Movement, Hematological System } \\
\text { Development and Function }\end{array}$ \\
\hline 14 & 15 & $\begin{array}{l}\text { Inflammatory Response, Cardiovascular System Development and } \\
\text { Function, Cell Morphology }\end{array}$ \\
\hline 13 & NA & Cancer, Cell Cycle \\
\hline 13 & 12 & Carbohydrate Metabolism, Lipid Metabolism \\
\hline Focus molecules & All with p<0.05 \\
\hline
\end{tabular}

Figure 3 Microarray and network analyses of cell lines. (a) Schematic of microarray analysis. In order to distinguish PPAR $\gamma$ isoform effects downstream of TZD treatment, PPAR $\gamma \mathrm{KO}$ cells (mPrE-PPAR $\gamma \mathrm{KO}+\mathrm{EV}$ ) were treated with Rosiglitazone (Rosi) and these Rosi-independent results (representing 82 genes, see Supplementary Figure 1a) were subtracted from the downstream regulation demonstrated in Rosi-treated PPAR $\gamma 1$ - (358 differentially regulated genes, see Supplementary Figure 1a) or PPAR 2 (400 differentially regulated genes, see Supplementary Figure 1a) rescued cells. Further analysis showed that 230 genes were differentially regulated in PPAR 1 versus PPAR $\gamma 2$-restored PPAR $\gamma 2$-rescued cells. $N=3$ for each of the four samples. (b) Top networks differentially regulated by PPAR $\gamma$ isoforms using INGENUITY

abundance of oleic acid (Figure 4c). As shown above, PPAR $\gamma 1$ expression also failed to induce prostatic differentiation (Figures 1 and 2), indicating that an increased availability of MUFAs through PPAR $\gamma 2$-mediated Scd1 expression may be beneficial for normal prostate epithelial differentiation.

As for other PPARs, ${ }^{21}$ we found using qRT-PCR that PPAR $\gamma 1$ and $-\gamma 2$ also regulated glucose metabolism genes, notably increasing Pdk4 expression (Table 1). Pdk4 phosphorylates and inactivates pyruvate dehydrogenase, resulting in the shunting of pyruvate toward lactate production rather than entry in the mitochondrial tricarboxylic acid (TCA) cycle. In tissues such as muscle, metabolic switching from glucose to fatty acid oxidation is mediated by increased Pdk4 expression. $^{24}$ To determine whether increased Pdk4 expression resulted in altered glucose/lactate flux, we collected conditioned media from mPrE-PPAR $\gamma \mathrm{KO}$ and the isoformrestored cells over a 4-day period. Results demonstrated a decrease in glucose flux in PPAR $\gamma$-restored cells (Figure 4d), coordinate with the level of Pdk4 expression (Table 1), with PPAR $\gamma 1$ mediating the strongest upregulation of Pdk4 and decrease in glucose consumption. A significant increase in lactate production was observed in PPAR $\gamma 2$-restored cells, indicating increased glycolytic metabolism. Furthermore, the increased glucose/lactate ratios observed in both PPAR $\gamma$ restored cells points to a clear shift away from glucose oxidation in the TCA cycle in favor of lactate production. Measurement of the IC50 of the glucose analog and oxidation inhibitor 2-deoxy-D-glucose (2DG) showed that mPrE$\mathrm{PPAR} \gamma \mathrm{KO}+\mathrm{EV}$ cells were significantly more sensitive to inhibition of glucose metabolism than their PPAR $\gamma$-restored counterparts (Figure $4 \mathrm{e}$ ), which are more likely to rely on fatty acid oxidation according to genes shown in Table 1.

These data demonstrate that although restoration of either PPAR $\gamma$ isoform in PPAR $\gamma$ KO HGPIN cells decreases de novo lipogenesis and oxidative stress, only PPAR $\gamma 2$-regulated genes induce a metabolic switch for induction of a prostatic differentiation program, potentially through disparate regulation of Scd1.

TZD or HFD treatment drives opposing effects on mouse prostate metabolism and differentiation in vivo. PPAR $\gamma$ has been hypothesized to provide a metabolic link between 

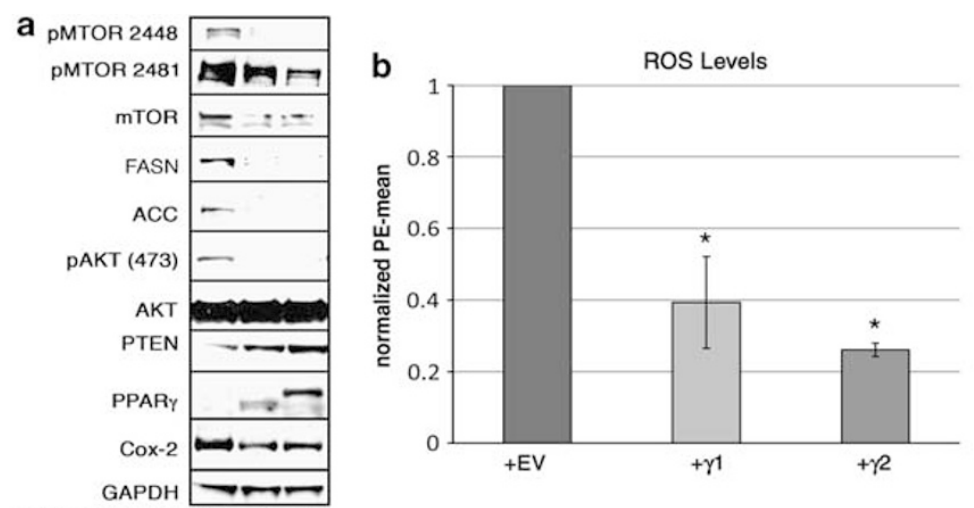

mPrE PPAR $Y K O+E V+\gamma 1+\gamma 2$

\begin{tabular}{|l|c|c|c|c|}
\hline mPrE PPAR $\gamma$ KO & +EV & +PPAR $\gamma$ 1 & +PPAR $\mathbf{2}$ & P value \\
\hline Saturated fatty acids & & & & \\
\hline $16: 0$ (palmitic) & $30.1+/-0.94$ & $32.6+/-1.10$ & $25.5+/-0.53$ & 0.0092 \\
\hline $18: 0$ (stearic) & $19.9+/-3.6$ & $30.6+/-0.50$ & $25.0+/-0.14$ & 0.0333 \\
\hline $\mathrm{n}-6$ Fatty acids & & & & \\
\hline $18: 2 \mathrm{n}-6$ (linoleic) & $7.5+/-0.88$ & $6.1+/-1.5$ & $8.3+/-0.22$ & 0.2366 \\
\hline $20: 3 \mathrm{n}-6$ (g-linoleic) & $\mathrm{ND}$ & $\mathrm{ND}$ & $\mathrm{ND}$ & \\
\hline $20: 4 \mathrm{n}-6$ (arachidonic) & $\mathrm{ND}$ & $\mathrm{ND}$ & $\mathrm{ND}$ & \\
\hline $\mathrm{n}-3$ Fatty acids & & & & \\
\hline $20: 5 \mathrm{n}-3$ (eicosapentanoic) & $0.48+/-0.02$ & $1.05+/-0.22$ & $0.89+/-0.24$ & 0.1142 \\
\hline $22: 5 \mathrm{n}-3$ (docosapentanoic) & $2.09+/-0.41$ & $3.8+/-0.60$ & $3.6+/-0.44$ & 0.0708 \\
\hline $22: 6 \mathrm{n}-3$ (docosahexanoic) & $3.18+/-0.76$ & $3.79+/-1.54$ & $3.35+/-0.21$ & 0.8298 \\
\hline $\mathrm{n}-7$ Fatty acids & & & & \\
\hline $16: 1 \mathrm{n}-7$ (palmitoleic) & $3.1+/-1.5$ & $4.2+/-3.3$ & $2.6+/-1.3$ & 0.7794 \\
\hline $18: 1 \mathrm{n}-7$ (vaccenic) & $6.6+/-0.43$ & $2.6+/-0.79$ & $5.9+/-0.79$ & 0.0196 \\
\hline $\mathrm{n}-9$ Fatty acids & & & & \\
\hline $18: 1 \mathrm{n}-9$ (oleic) & $29.2+/-1.1$ & $18.8+/-2.9$ & $28.3+/-3.9$ & 0.0408 \\
\hline total levels & $7.2+/-2.6$ & $13.8+/-1.2$ & $8.8+/-2.6$ & 0.1175 \\
\hline
\end{tabular}
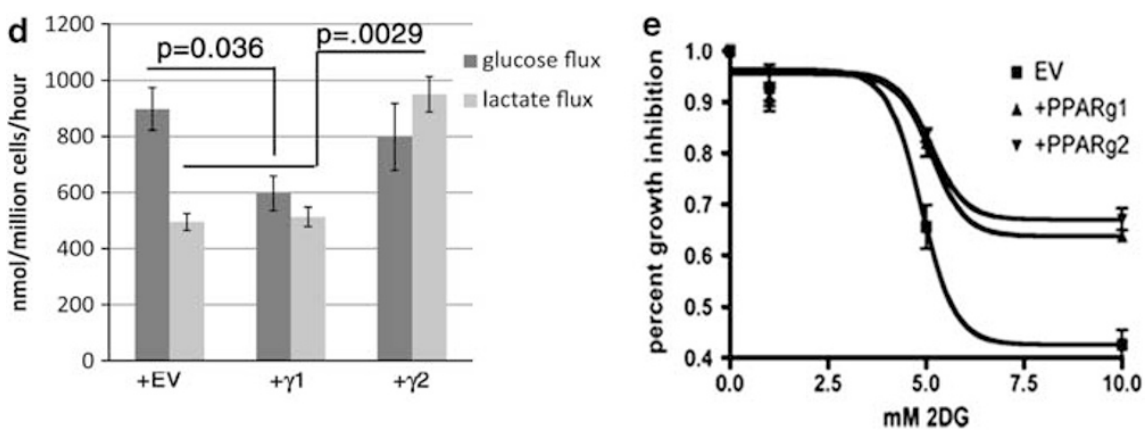

Figure 4 PPAR $\gamma$ isoforms equally decrease de novo lipogenesis and oxidative stress, but differentially modulate triglyceride saturation and glucose metabolism. (a) Ectopic expression of PPAR $\gamma 1$ or PPAR $\gamma 2$ in mPrE-PPAR $\gamma$ KO cells resulted in decreased activation of lipogenic pathways including Akt, mTOR, Fasn and Acc. In addition, Cox-2 levels were decreased indicative of lower levels of ROS. (b) Dihydroethidium staining followed by flow cytometry $(\mathrm{N}=3)$ confirmed a decrease in ROS. (c) Fatty acid analysis of triglycerides by TLC/MS revealed increased levels and saturation of stearic acid (increased 18:0, decreased 18: 1n9) in PPAR $\gamma$ 1-restored cells compared to + EV cells $(\mathrm{N}=3$ ), consistent with the decreased expression of Scd1 (see Table 1). (d) Glucose/lactate flux analysis in mPrE-PPAR $\gamma \mathrm{KO}+\mathrm{EV},+\mathrm{PPAR} \gamma 1$ or + PPAR 2 cells over 4 days (2 time points/day) demonstrated significantly decreased glucose uptake in mPrE-PPAR $\gamma K O+P P A R \gamma 1$ cells and significantly increased lactate secretion in $\mathrm{mPrE}-\mathrm{PPAR} \gamma \mathrm{KO}+\mathrm{PPAR} \gamma 2$ cells compared to + EV cells. (e) IC50 analysis of the glucose oxidation inhibitor 2DG suggested a reliance of mPrE-PPAR $\gamma \mathrm{KO}+\mathrm{EV}$ cells on glucose in the absence of + PPAR $\gamma 1$ or + PPAR $\gamma 2$ cells, which highly regulate fatty acid transport and metabolism (see Table 1 ). ${ }^{*} P$ value $<0.05$

obesity and tissue dysfunction. ${ }^{13}$ In order to determine whether TZDs or obesity affect PPAR $\gamma$-mediated prostatic differentiation in vivo, we fed male mice a Western diet or Rosiglitazone chow for 6 months and examined their prostates for changes in morphology (Figure 5) and PPAR $\gamma$-regulated genes (Table 2). Significant increases in overall animal weight were detected following HFD treatment only (Figure $5 \mathrm{a}$ ). Notable increases in smooth muscle density were observed with TZD treatment (Figure 5d), with little epithelial hyperplasia. In addition, intra-muscular adipocytes were also highly enriched in TZD-treated animals (Figure 5d, star), which made clean dissection for RNA analysis of prostate-specific genes extremely difficult. This is consistent with the deposition of intramuscular adipocytes in skeletal muscle of TZD-treated human subjects. ${ }^{25}$ Although PPAR 2 is thought of as an adipose-specific gene, we were able to demonstrate using a PPAR $\gamma 2$-specific antibody that it is also expressed sporadically in mouse prostate luminal epithelia (Figure 5f) as well as throughout the smooth muscle (Figure 5b).

As shown in Table 2, large increases in PPAR $\gamma$-regulated genes were observed in TZD-treated animals. Given the 


\begin{tabular}{|c|c|c|c|c|c|c|}
\hline \multirow[b]{2}{*}{ Gene } & \multirow[b]{2}{*}{ Function } & \multirow[b]{2}{*}{ Cellular localization } & \multicolumn{2}{|c|}{+ PPAR $\gamma 1$} & \multicolumn{2}{|c|}{+ PPAR $\gamma 2$} \\
\hline & & & Fold induction & $P$ value & Fold induction & $P$ value \\
\hline \multicolumn{7}{|c|}{ I. Metabolic genes } \\
\hline Acot1 & Long chain fatty acid metabolism & Cytoplasm & 19.0 & 0.09 & 304.3 & $<0.05$ \\
\hline Acsf2 & Fatty acid oxidation & Mitochondrion & 69.1 & $<0.05$ & 109.7 & 0.10 \\
\hline Adipor1 & Fatty acid oxidation & Plasma membrane & 1.7 & $<0.05$ & 2.7 & $<0.05$ \\
\hline Cd68 & Fatty acid transport & Lysosome & 2.1 & 0.27 & 11.8 & $<0.05$ \\
\hline Cd36 & Long chain fatty acid metabolism & Cytoplasm, mitochondrion & 3.2 & 0.09 & 32.1 & $<0.05$ \\
\hline Dagla & Lipolysis & Plasma membrane & 3.5 & $<0.05$ & 5.5 & 0.08 \\
\hline Dgat2 & Triglyceride synthesis & Endoplasmic reticulum & 1.4 & 0.10 & 3.3 & 0.08 \\
\hline Elovl4 & Fatty acid elongation & Endoplasmic reticulum & -2.6 & 0.09 & 1.3 & 0.41 \\
\hline Fabp4 & Fatty acid transport & Cytoplasm, nucleus & 72.7 & $<0.05$ & 220.3 & $<0.05$ \\
\hline Fbp2 & Carbohydrate metabolism & Cytoplasm & -3.7 & $<0.05$ & 2.1 & 0.11 \\
\hline Fetub & Insulin responsiveness & Extracellular & 3.2 & 0.30 & 2.4 & 0.13 \\
\hline Gls2 & Glutamine synthesis & Mitochondrion & -1.3 & 0.52 & -1.2 & 0.48 \\
\hline Glul & Glutamine catabolism & Mitochondrion & 1.7 & 0.25 & 2.9 & 0.16 \\
\hline Lipa & Lipolysis & Lysosome & 3.7 & $<0.05$ & 6.1 & $<0.05$ \\
\hline Lpl & Lipolysis & Plasma membrane & 15.4 & $<0.05$ & 121.1 & $<0.05$ \\
\hline Lrp1 & Fatty acid transport & Plasma membrane & 2.1 & 0.10 & 8.3 & $<0.05$ \\
\hline Pdk4 & Carbohydrate metabolism & Mitochondrion & 17.4 & $<0.05$ & 5.1 & $<0.05$ \\
\hline Pparg & Nuclear receptor & Nucleus & 8.7 & 0.06 & 64.6 & $<0.05$ \\
\hline Ppargc1a & Pparg cofactor & Nucleus & 6.0 & 0.09 & 23.9 & $<0.05$ \\
\hline Ppargc1b & Pparg cofactor & Nucleus & 1.5 & 0.30 & 2.2 & 0.19 \\
\hline Scd1 & Fatty acid desaturase & Endoplasmic reticulum & -2.2 & 0.07 & 2.6 & $<0.05$ \\
\hline Txnip & Carbohydrate metabolism & Mitochondrion & 1.1 & 0.64 & 7.9 & 0.08 \\
\hline \multicolumn{7}{|c|}{ II. Oxidative stress genes } \\
\hline Aldh1a1 & Oxidative stress & Cytoplasm & 1.3 & 0.28 & 9.2 & 0.06 \\
\hline Aldh1a7 & Oxidative stress & Cytoplasm & 2.0 & 0.12 & 8.7 & $<0.05$ \\
\hline Aldh3a1 & Oxidative stress & Cytoplasm & 4.8 & 0.19 & 11.8 & $<0.05$ \\
\hline Aldh3b1 & Oxidative stress & Cytoplasm & 3.7 & 0.16 & 9.7 & $<0.05$ \\
\hline Aldh7a1 & Oxidative stress & Cytoplasm & 4.9 & $<0.05$ & 2.9 & 0.12 \\
\hline Aox3 & Oxidative stress & Cytoplasm & 105.9 & 0.20 & 92.6 & $<0.05$ \\
\hline Casp4 & Cell death & Endoplasmic reticulum & 5.0 & $<0.05$ & 21.6 & $<0.05$ \\
\hline Cat & Oxidative stress & Mitochondrion & 1.2 & 0.36 & 4.1 & $<0.05$ \\
\hline Cyp17a1 & Oxidative stress & Mitochondrion & 3.5 & $<0.05$ & 4.5 & 0.09 \\
\hline Dhrs3 & Oxidative stress & Plasma membrane & 13.8 & 0.23 & 31.9 & $<0.05$ \\
\hline Gsta2 & Oxidative stress & Cytoplasm & 3.9 & 0.07 & 18.7 & 0.24 \\
\hline Sirt5 & Oxidative stress & Mitochondrion & 1.9 & 0.13 & 2.8 & 0.08 \\
\hline Sod3 & Oxidative stress & Extracellular & 5.1 & $<0.05$ & 8.1 & 0.11 \\
\hline \multicolumn{7}{|c|}{ III. Differentiation genes } \\
\hline$A r$ & Steroid receptor & Cytoplasm, nucleus & 3.5 & $<0.05$ & 10.8 & $<0.05$ \\
\hline Krt14 & Basal cell keratin & Plasma membrane & -1.2 & 0.60 & 4.1 & 0.14 \\
\hline Pbsn & Prostate-specific differentiation & Extracellular & -1.7 & 0.41 & 2.7 & 0.19 \\
\hline Pten & Lipid and protein phosphatase & Plasma membrane & 1.5 & 0.14 & 2.7 & $<0.05$ \\
\hline Trp63 & Basal cell marker & Nucleus & 3.3 & $<0.05$ & 8.0 & 0.17 \\
\hline Acta2 & Smooth muscle marker & Structural & 1.5 & 0.28 & 1.9 & $<0.05$ \\
\hline
\end{tabular}

increase in intraprostatic adipocytes after TZD treatment, it was unclear whether these changes were regulated in adipocytes or prostate. Therefore, immunohistochemistry was performed on metabolic proteins including Scd1, Lpl, Cd36, Fabp4 and Pdk4. Although ectopic PPAR $\gamma$ expression was able to regulate some of the fatty acid metabolism genes in vitro (Table 1), immunoreactivity for Fabp4 (Supplementary Figure 1c), Lpl and Scd1 was low in mouse prostate and high in adjacent adipocytes, likely reflecting the strong increases in RNA expression shown in Table 2, Section II. However, immunoreactivity for $\mathrm{Cd} 36$ (expressed in epithelia and stroma, Supplementary Figure 1b) and Pdk4 (expressed in epithelia, Figure $51-n$ ) were strong, suggesting that these genes might be important in directly mediating the metabolism and differentiation of prostate, versus Fabp4 and Lpl, which may indirectly mediate prostate differentiation through adjacent adipocyte fatty acid metabolism.

As PPAR $\gamma$-regulated genes were so drastically affected in TZD-treated animals, epididymal white adipose tissue (eWAT) gene expression was also examined by qRT-PCR under normal conditions or TZD treatment and was directly compared with that of prostate (Table 2, row 1 versus row 2). Results are compartmentalized into genes predominantly regulated by TZD in either eWAT (I) or prostate (II) or both (III). Contrary to common perceptions of both adipose and prostate, total PPAR $\gamma$ levels (isoforms were not discriminated by qRT-PCR) were higher in prostate than eWAT under normal feeding conditions and AR levels were equivalently expressed (contamination by adipocytes in prostates of animals fed regular chow was minimal). However, under 

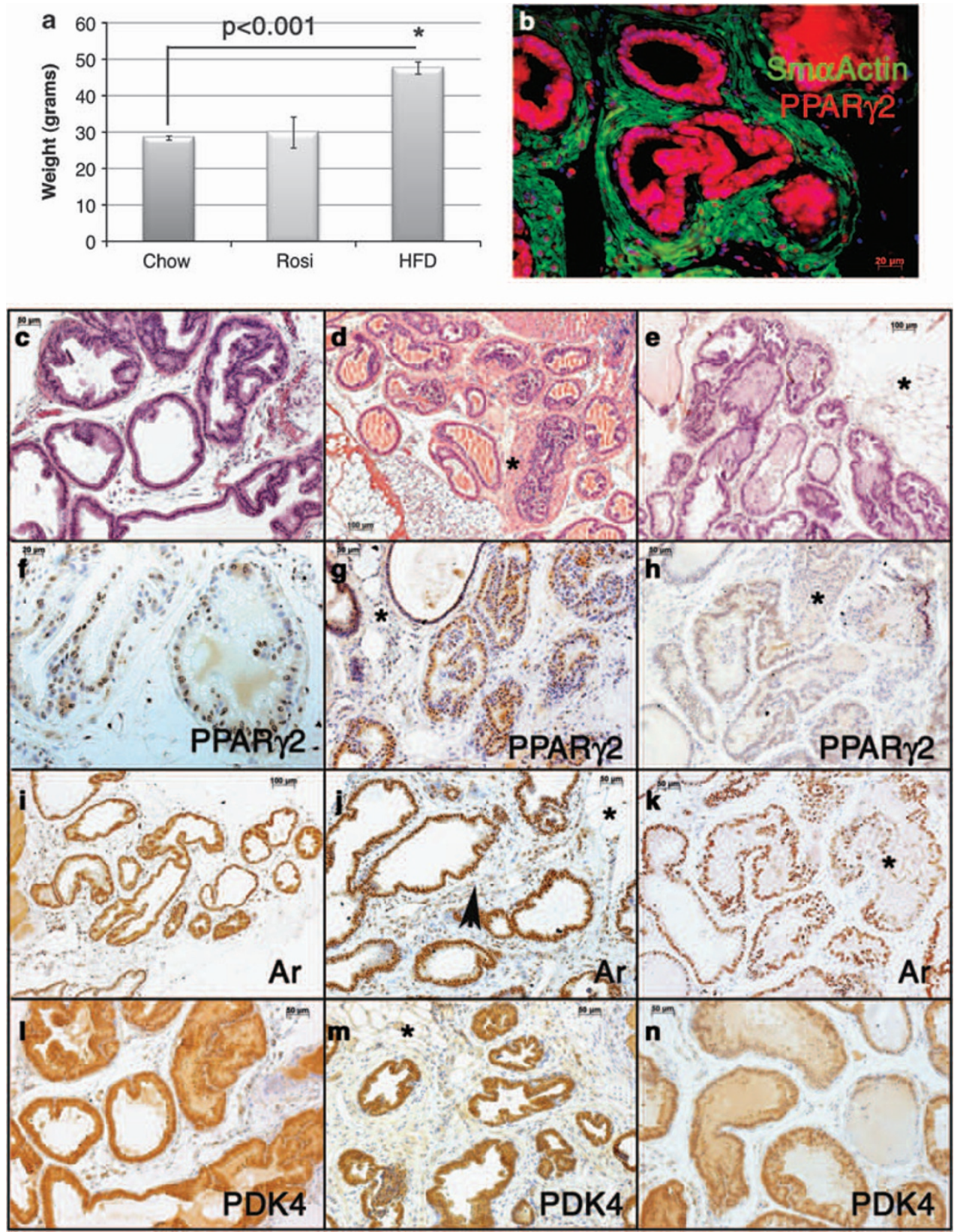

Figure 5 Administration of TZD or HFD drives opposing effects on mouse prostate metabolism and differentiation in vivo. (a) Western diet-, but not TZD-fed animals significantly increased total weights by $20 \mathrm{~g}(N=3$ each). (b) PPAR 22 is coexpressed in prostate smooth muscle. (c-n) C57B male mice were fed control (a, f, i and I), Rosiglitazone $(\mathbf{b}, \mathbf{g}, \mathbf{j}$ and $\mathbf{m})$ or Western diet chow $(\mathbf{e}, \mathbf{h}, \mathbf{k}$ and $\mathbf{n})$ for 6 months. PPAR 2 levels were similar in prostate epithelia after TZD treatment (f versus $\mathbf{g})$ but decreased in some acini of HFD-treated animals ( $\mathbf{h}$, star). Intramuscular adipocytes were increased in TZD-treated animals (g, star), which also resulted in increased AR expression increased in smooth muscle (j, arrow). AR expression was decreased in HFD-treated animals ( ${ }^{*}$ in $\mathbf{k}$ ) similar to qRT-PCR analysis (see Table 2). PDK4 expression was similar in prostate tissue of TZD-treated animals ( $\mathbf{m},{ }^{*}$ indicates adipose) and decreased in HFD-treated animals (n) (see Table 2)

TZD treatment, $A R$ (and probasin) levels increased in prostate and not eWAT. Notably, PPAR $\gamma 2$ is allostatically induced in adipose under HFD, ${ }^{26}$ which could explain the lower levels of total PPAR $\gamma$ in lean mouse eWAT versus prostate. Recent evidence of the molecular signature of various adipose depots could also explain the difference in PPAR $\gamma$-regulated genes in eWAT versus the intramuscular adipose of TZD-treated prostate, ${ }^{27}$ which may indicate the expansion of highly metabolic brown adipose shown previously to be regulated by TZDs. ${ }^{28}$

Other notable differences between prostate and eWAT gene expression patterns included numerous oxidative stress genes (Cat, Gsta2, Sirt5, Nox1, Nfkb2) and the triglyceridesynthesizing enzyme Dgat2, which were highly enriched in adipose versus prostate. However, a number of fatty acid metabolism (Acsf2, Adipor1, Cd36, Lpl) and differentiation 


\begin{tabular}{|c|c|c|c|c|c|c|}
\hline \multirow[b]{2}{*}{ Gene } & \multirow[b]{2}{*}{ Function } & \multirow[b]{2}{*}{ Cellular localization } & \multicolumn{4}{|c|}{ Fold induction } \\
\hline & & & $\begin{array}{l}\text { Prostate versuse } \\
\text { WAT (-TZD) }\end{array}$ & $\begin{array}{l}\text { eWAT } \\
(+ \text { TZD })\end{array}$ & $\begin{array}{l}\text { Prostate } \\
\text { (+ TZD) }\end{array}$ & $\begin{array}{c}\text { Prostate } \\
\text { (HFD) }\end{array}$ \\
\hline \multicolumn{7}{|c|}{ I. TZD-regulated genes in adipose } \\
\hline Dgat2 & Triglyceride synthesis & Endoplasmic reticulum & 2459.2 & 4.4 & 53.1 & 8.3 \\
\hline Elov14 & Fatty acid elongation & Endoplasmic reticulum & 16.5 & 4.0 & -1.3 & -9.4 \\
\hline Fetub & Insulin responsiveness & Extracellular & 223.3 & 5.7 & -96.8 & 124.6 \\
\hline Gsta2 & Oxidative stress & Cytoplasm & 21.5 & 115.5 & -1.5 & -9.7 \\
\hline Ppargc1b & Pparg cofactor & Nucleus & 6.3 & 1.9 & -2.0 & 5.1 \\
\hline Sirt5 & Oxidative stress & Cytoplasm & 1492.8 & 1.4 & -1.9 & -11.5 \\
\hline Trp63 & $\begin{array}{l}\text { Prostate basal cell/adipocyte } \\
\text { marker }\end{array}$ & Nucleus & 153.9 & 2.1 & -36.3 & 6.2 \\
\hline Nox1 & Oxidative stress & Cytoplasm & 508.9 & 2.7 & -1.1 & -1.3 \\
\hline Nfkb2 & Oxidative stress, inflammation & Cytoplasm, nucleus & 63.8 & 2.9 & -3.2 & -1.5 \\
\hline \multicolumn{7}{|c|}{ II. TZD-regulated genes in prostate } \\
\hline Acsf2 & Fatty acid oxidation & Mitochondrion & 5.7 & 1.1 & 6.2 & -5.4 \\
\hline Acta2 & Smooth muscle marker & Structural & -2.3 & 2.7 & 9.5 & -41.2 \\
\hline Adipor1 & Fatty acid oxidation & Plasma membrane & 2.0 & 2.3 & 97.7 & -171.4 \\
\hline$A r$ & Steroid receptor & Cytoplasm, nucleus & 1.4 & 2.1 & 33.8 & -81.1 \\
\hline Cd36 & Long chain fatty acid metabolism & Cytoplasm, mitochondrion & -1.4 & 4.7 & 48.3 & 3 \\
\hline Cd68 & Fatty acid transport & Lysosome & -3.7 & 2.8 & 473.5 & -31.3 \\
\hline Dagla & Lipolysis & Plasma membrane & -2.9 & -1.0 & 7.8 & -77.4 \\
\hline Fabp4 & Fatty acid transport & Cytoplasm, nucleus & -252.5 & 7.3 & 7669.7 & -169.6 \\
\hline Fbp2 & Carbohydrate metabolism & Cytoplasm & -1.8 & 11.0 & 122.3 & -13.6 \\
\hline Glul & Glutamine catabolism & Mitochondrion & -26.8 & 1.6 & 223.2 & -57.8 \\
\hline Krt14 & Basal cell keratin & Plasma membrane & 1.8 & -2.5 & 5.2 & -5.1 \\
\hline Lpl & Lipolysis & Plasma membrane & 4.1 & 7.8 & 1035.7 & -4.7 \\
\hline Pbsn & Prostate-specific differentiation & Extracellular & -135.3 & -1.6 & 414.3 & -249.9 \\
\hline$P d k 4$ & Carbohydrate metabolism & Mitochondrion & 2.3 & 14.7 & 7047.8 & -57.3 \\
\hline Tgm2 & Wound healing & Cytoplasm, nucleus & 7.8 & 11.6 & 9939.9 & -123.4 \\
\hline \multicolumn{7}{|c|}{ III. TZD-regulated genes in adipose and prostate } \\
\hline$A \cot 1$ & Long chain fatty acid metabolism & Cytoplasm & 3.0 & 36.5 & 38.9 & -254.1 \\
\hline Cat & Oxidative stress & Mitochondrion & 250.3 & 5.4 & 68.0 & -9.4 \\
\hline Lipa & Lipolysis & Lysosome & 9.8 & 2.1 & 4.7 & -1.5 \\
\hline Pparg & Nuclear receptor & Nucleus & -11.3 & 9.7 & 76.1 & -3.7 \\
\hline Ppargc1a & Pparg cofactor & Nucleus & 31.5 & 5.8 & 5.1 & -2.8 \\
\hline Pten & Protein and lipid phosphatase & Cytoplasm, nucleus & 36.2 & 1.7 & 49.7 & -97.9 \\
\hline Scd1 & Fatty acid desaturase & Endoplasmic reticulum & 21.9 & 13.2 & 128.0 & -4.3 \\
\hline Txnip & Carbohydrate metabolism & $\begin{array}{l}\text { Plasma membrane, } \\
\text { nucleus }\end{array}$ & 1.0 & 14.7 & 60.0 & -2.4 \\
\hline
\end{tabular}

( $A R$, probasin) genes were equally high in prostate, including the glucose oxidation inhibitor, Pdk4, which suggests that the differentiation induced by PPAR $\gamma$ expression shown here may represent a metabolically regulated program of prostatic differentiation in vivo.

Given the regulation of prostate differentiation by PPAR $\gamma 2$ in mouse, we also wanted to confirm the expression of PPAR 22 and some of its downstream-regulated genes in human prostate tissue. Figure $6 a$ shows that PPAR $\gamma 2$ is highly enriched in prostate smooth muscle and that Scd1 (upregulated by PPAR $\gamma 2$ expression in vitro) is highly enriched in prostate basal cells (Figure 6b). Furthermore, CD36 was expressed in both epithelia and smooth muscle (Figure 6c), whereas PDK4 was expressed predominantly in epithelia (Figure 6d). The compartmentalization of cellular glucose and fatty acid metabolism (Figure 6e) suggests a model of stromal-epithelial, as well as basal-luminal interactions whose disruption by systemic metabolic disease may adversely affect the health and differentiation of prostate (Figure 6f). These results suggest that PPAR $\gamma$ is a major metabolic regulator in the control of mouse and human prostate differentiation.

\section{Discussion}

A recent study of the global prevalence of glycemia and diabetes demonstrated an increase from 153 million affected individuals in 1980 to 347 million in $2008,{ }^{29}$ which, according to epidemiological correlations, will likely have a major direct impact on prostate disease incidence. Upon maximal lipid storage capacity of white adipose tissue (WAT), peripheral tissues begin to store lipid in excess of their natural oxidative or storage capacity resulting in lipotoxicity, inflammation and eventually insulin resistance. ${ }^{30}$ Recent evidence squarely positions prostatic diseases as sequelae of systemic metabolic dysfunction, including hyperinsulinemia, hyperglycemia and hypercholesterolemia ${ }^{31}$; however, the underlying etiologies of such susceptibilities remain unknown largely because of the absence of a molecular understanding of the basic metabolic machinery governing prostatic function.

Here, we demonstrate that expression of PPAR $\gamma 2$ drives benign prostate epithelial cell differentiation. In mouse prostate PPAR $\gamma 2$ was expressed in both smooth muscle and epithelium (Figures $5 b$ and $f$ ), whereas in human prostate PPAR $\gamma 2$ expression seems to be restricted to smooth muscle 


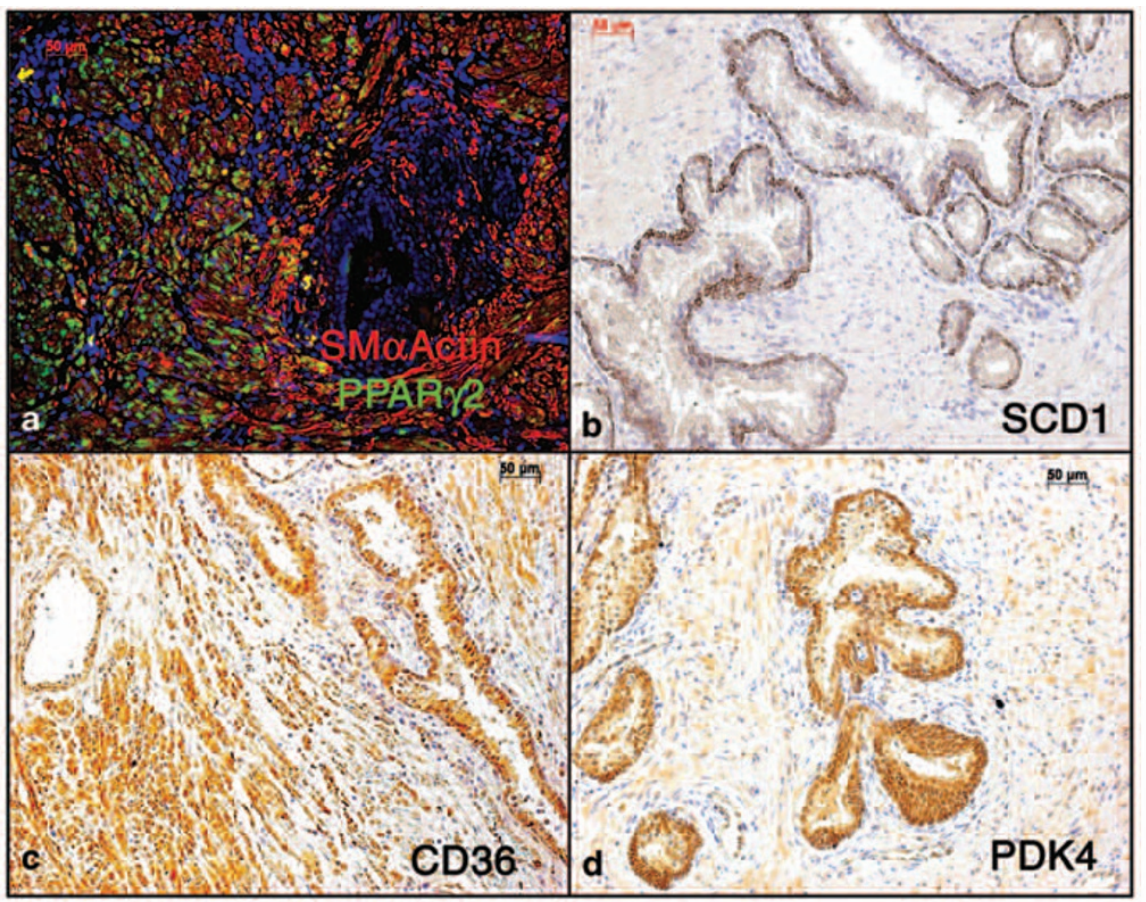

e

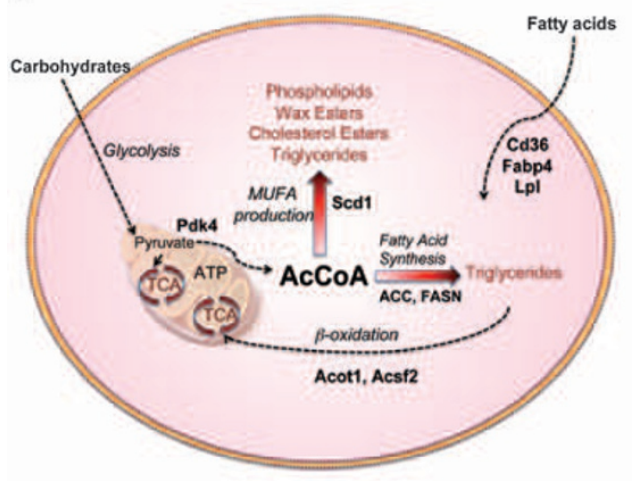

f

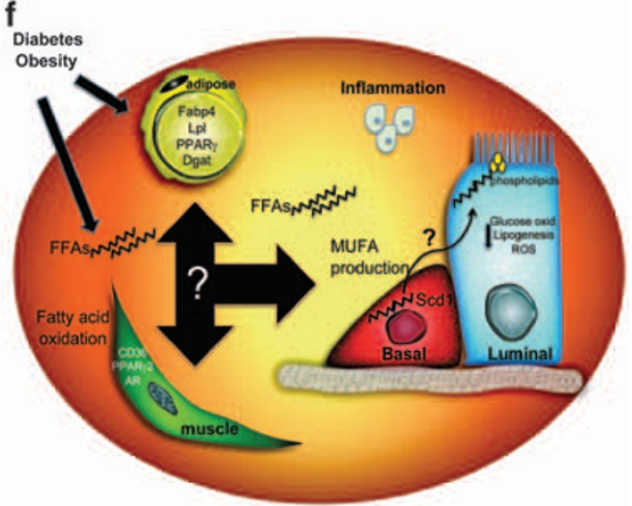

Figure 6 PPAR $\gamma$-regulated genes in human prostate tissues. (a) Double staining for PPAR $\gamma 2$ and alpha smooth muscle actin $(\alpha$-SMA) by immunofluorescence revealed colocalization in a subset of smooth muscle. (b) SCD1 expression is enriched in prostate basal epithelia by immunohistochemical staining (IHC). (c) CD36 is expressed in smooth muscle and epithelia. (d) PDK4 is expressed predominantly in the epithelium. (e) Cellular model of metabolic genes and functions regulated by PPAR $\gamma$. (f) Tissue interaction model of the potential role of paracrine fatty acid metabolism in regulating prostate differentiation and diseases as comorbidities of diabetes and obesity

(Figure 6a). Stromal-epithelial interactions have long been recognized to have a role in prostate differentiation, ${ }^{32}$ but the underlying mechanisms remain elusive. These data suggest that paracrine fatty acid metabolism may drive epithelial differentiation, resulting in decreased glucose metabolism, oxidative stress and lipogenesis (Figure 4).

PPAR $\gamma$ has been shown to regulate the balance between glucose and lipid oxidation in a tissue-specific manner. ${ }^{33}$ Here, we show that TZD treatment upregulated markers of prostatic differentiation in correlation with an increase in highly metabolic smooth muscle and intramuscular adipose (Figure 5, Table 2), which also correlated with the decreased glucose flux and lipogenesis shown in PPAR $\gamma$-restored cells in vitro (Figure 2).

The isoform-specific effects of PPAR $\gamma$ have not been directly compared in any tissue. One of the most interesting genes differentially regulated by PPAR $\gamma$ isoforms in prostate was the fatty acid desaturase Scd1. Systemic deletion of Scd1 provides protection against obesity due to reduced fatty acid and triglyceride synthesis as well as increased oxidation. ${ }^{22,23}$ In contrast to other tissues, SCD1 expression is high in human prostate epithelia, but its expression and role in prostate cancer has been debated. ${ }^{34,35}$ Moreover, PPAR $\gamma 2$ upregulated Scd1 expression and drove basal cell differentiation (Figure 2), and SCD1 was shown to be predominantly restricted to the basal cell compartment of normal human prostate (Figure $6 \mathrm{~b}$ ) whereas PPAR $\gamma 2$ was predominantly expressed in smooth muscle (Figure 6a). As modeled in Figure 6f, these data led us to hypothesize that PPAR $\gamma 2$-mediated import and oxidation of fatty acids may dictate prostate basal cell differentiation through increased SCD1. 
Tissue-specific effects of PPAR $\gamma$ agonization have demonstrated that the upregulation of liver fatty acid and sterol synthesis in HFD-fed rats could be reversed by PPAR agonists, whereas the same HFD stimulated PPAR $\gamma$ downregulation and lipogenesis in muscle. ${ }^{13}$ Concordant with studies demonstrating positive effects of TZDs on HFD mouse prostates, $^{36,37}$ we demonstrated here that chronic HFD treatment resulted in decreased androgen signaling and low-grade PIN, coordinate with decreased PPAR $\gamma$ signaling (Figure 5, Table 2). These data suggest that an allostatic response to downregulate fatty acid import and metabolism may negatively affect prostate differentiation through metabolic switching.

Cells access and metabolize fatty acids through the activities of lipases (e.g., Lpl, Lipa), transporters (e.g., Fabp4, Cd36) and enzymes (acyl-coa synthetases, thioesterases), which supply the cell with acetyl coenzyme A (acetyl-CoA) for eventual entry into mitochondria for energy production. Alternatively, acetyl-CoA can be used as a building block for MUFA production (Scd1) and subsequently converted into triglycerides, cholesterol esters and phospholipids (Figure 6e). The therapeutic efficacy of targeting fatty acid metabolism (synthesis, modification, transport and oxidation) has had some success, but off-target effects have limited their broad usage. ${ }^{10}$ Similarly, more selective drugs targeting PPAR $\gamma$ and Scd1 promising fewer side effects are being pursued. ${ }^{22,38}$ Future studies must be able to link changes in systemic metabolism to local metabolic changes in prostate, which mandates a deeper understanding of the fundamental metabolic infrastructure regulating prostatic differentiation and what allostatic changes may occur in response to systemic metabolic stress. The data presented here suggest that a microenvironment of PPAR $\gamma 2$-mediated fatty acid metabolism by stroma or adipose may drive prostatic epithelial differentiation; however, under conditions of diabetes and obesity fatty acid supply may become saturated, leading to inflammation and hyperplasia in prostate disease (Figure 6f).

\section{Materials and Methods}

Generation of cell lines, microarray studies and qRT-PCR. mPrEPPAR $\gamma$ KO cells were spontaneously immortalized from an adult PBCre4t ${ }^{\text {tg }} 0$, PPAR $\gamma^{\text {flox } f \text { flox }}$ double-transgenic male mouse. ${ }^{17}$ The pQCXIP-empty vector, mouse PPAR $\gamma 1$ or PPAR $\gamma 2$ wild-type full-length cDNA (gifts from Drs. Y Eugene Chen and Jifeng Zhang, University of Michigan Medical Center) were stably transfected into the mPrE-PPAR $\gamma \gamma \mathrm{KO}$ cells to generate mPrEPPAR $\gamma \gamma \mathrm{KO}+\mathrm{EV}, \mathrm{mPrE}-\mathrm{PPAR} \gamma \mathrm{KO}+\mathrm{PPAR} \gamma 1$ or mPrE-PPAR $\gamma \mathrm{KO}+\mathrm{PPAR} \gamma 2$ cell line, respectively. ${ }^{17}$

Microarray and network analyses and qRT-PCR validation. RNA was isolated with Trizol (Ambion, Austin, TX, USA) and reverse transcribed by RNeasy columns (Qiagen, Valencia, CA, USA) followed by reverse transcription (Qiagen) for hybridization on mouse Genechip St. 1.0 microarrays using triplicate samples from each cell line treated with $5 \mu \mathrm{M}$ Rosiglitazone (Rosi) (Cayman Chemical, Ann Arbor, MI, USA) as well as mPrE-PPAR $\gamma$ KO + EV without Rosi. PPAR $\gamma$-independent effects of Rosi generated in mPrE-PPAR $\gamma \mathrm{KO}+\mathrm{EV}$ cells were subtracted from results comparing mPrE-PPAR $\gamma \mathrm{KO}+\mathrm{EV}$ versus PPAR $\gamma$ restored cells. SAM was used to stringently select $(F D R<0.05)$ statistically significant genes. Both SAM and unsupervised hierarchical clustering analysis were carried out using TIGR MeV program. Their possible networks and canonic pathways were identified using INGENUITY software (https://apps.ingenuity.com). Custom qRT-PCR plates manufactured by SABiosciences (Valencia, CA, USA) were designed to analyze selected PPAR $\gamma$-regulated genes in Rosi-treated $\mathrm{mPrE}$ -
PPAR $\gamma \mathrm{KO}+\mathrm{EV}, \mathrm{mPrE}-\mathrm{PPAR} \gamma \mathrm{KO}+\mathrm{PPAR} \gamma 1$ and $\mathrm{mPrE}-\mathrm{PPAR} \gamma \mathrm{KO}+\mathrm{PPAR} \gamma 2$ cell lines in triplicate. Results were analyzed using SABiosciences qRT-PCR analysis software (SABiosciences.com) and represented fold changes based on $\Delta \Delta C_{\mathrm{t}}$ analysis.

Detection of ROS. Each cell line was grown to confluence, trypsinized, washed and incubated with $1 \mu \mathrm{M}$ Dihydroethidium (Life Technologies, Carslbad, CA, USA) for $15 \mathrm{~min}$ followed by three washes in PBS. Flow cytometry was then performed and results represent the average mean intensity $(N=3)$. Statistical analysis was performed by GraphPad Prism software (La Jolla, CA, USA) using Student's unpaired $t$ test.

Fatty acid profile (TLC/MS). Lipid class separation and fatty acid identification of cell lines were performed by the Vanderbilt Hormone Assay and Analytical Services Core (http://hormone.mc.vanderbilt.edu/). Briefly, the Folch method of lipid extraction ${ }^{39}$ was followed by thin layer chromatography (TLC) was used to isolate triglycerides. Fatty acid analysis was performed by mass spectrometry (MS) with internal standards. Total triglycerides were normalized to protein concentration as determined by the Lowry method. Statistical analysis was performed on triplicate samples by GraphPad Prism software using one way ANOVA test.

Luciferase assay. Cells were grown to $70 \%$ confluency in 12-well culture plates and cotransfected with pRL-null $(0.16 \mu \mathrm{g} / \mathrm{well})$ and ARR2PB-Luciferase $(1.44 \mu \mathrm{g} /$ well) using $4 \mu \mathrm{l}$ Lipofectamine 2000 in OptiMEM (Invitrogen, Grand Island, NY, USA). After $24 \mathrm{~h}$ transfection, media was replaced with $10 \%$ charcoalstripped FBS in DMEM plus or minus $10^{-8} \mathrm{M} \mathrm{DHT}$ and incubated for $24 \mathrm{~h}$. At this time, cells were lysed and dual luciferase activity measured using the Dual Luciferase Reporter Assay System (Promega, Madison, WI, USA) on a Turner

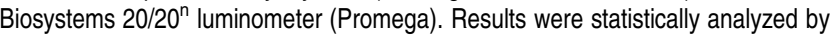
Student's unpaired $t$ test $(N=3)$ using GraphPad Prism.

Western blot. Western blotting was performed as described previously. ${ }^{17}$ Briefly, $30 \mu \mathrm{g}$ protein was loaded on $10 \%$ SDS acrylamide gels (Life Technologies) and transferred onto PVDF membranes (Millipore, Temecula, CA, USA). The following antibodies were used for detection: mTOR, phospho-mTOR, PTEN, ACC and AKT, phospho-AKT (S473) were from Cell Signaling (1:1000, Danvers, MA, USA), Cox-2 (1:500, Millipore), AR and PPARy $(1: 250$, Santa Cruz Biotechnology, Santa Cruz, CA, USA), FASN (1:1000, GeneTex, Irvine, CA, USA), Gapdh (1: 1000, Abcam, Cambridge, MA, USA) and Ck14 (1:1000, Vector Labs, Burlingame, CA, USA). Blots were then incubated with secondary antibodies (1:1000, anti-mouse, anti-rabbit from GE Healthcare, Buckinghamshire, UK) for $45 \mathrm{~min}$ in $5 \%$ milk in TBST, washed and developed with Western Lightning PlusECL (Perkin Elmer, Waltham, MA, USA).

ICC/IHC. ICC/IHC was performed as described previously. ${ }^{17}$ Briefly, cells were cultured on glass chamber slides (LabTek II, Naperville, IL, USA), washed with PBS, fixed in 4\% PFA for $15 \mathrm{~min}$, blocked in $12 \%$ BSA for $1 \mathrm{~h}$ and incubated with primary antibodies (1:25 PPAR $\gamma$, Santa Cruz; 1:50 CK14, Vector Labs; 1: 100 AR, Santa Cruz; $1: 500 \mathrm{Ck} 8 / 18$, Fitzgerald, Acton, MA, USA) in $12 \% \mathrm{BSA}$ at $4{ }^{\circ} \mathrm{C}$ overnight followed by incubation with a fluorescent secondary antibody $(1: 1000$, Molecular Probes, Eugene, OR, USA) for $45 \mathrm{~min}$ at $37^{\circ} \mathrm{C}$. Cells were counterstained and mounted with Dapi Vectashield (Vector Labs) and images were taken on a Zeiss Axioplan microscope. Tissues harvested from grafted (kidney capsule) or TZD- or HFD-treated mice (epididymal WAT, prostate) were fixed in $10 \%$ formalin at $4^{\circ} \mathrm{C}$ overnight, paraffin embedded and then $5 \mu \mathrm{M}$ sections cut for immunohistochemistry. Slides were deparaffinized, rehydrated and endogenous peroxidases blocked with $2 \% \mathrm{H}_{2} \mathrm{O}_{2}$ in methanol. Following citrate retrieval and blocking with $5 \%$ goat serum, slides were incubated at $4{ }^{\circ} \mathrm{C}$ overnight with the following antibodies: AR (1:200, Santa Cruz), PPAR 2 ( $1: 200$, Abcam), smooth muscle actin (1:2000 Invitrogen), Ck14 (1:100), CK18 (1:500), PDK4 ( $1: 500$, ProteinTech, Chicago, IL, USA). Secondary antibodies for IHC were from Dako (Carpinteria, CA, USA) and used at $1: 200$ dilution. Secondary antibodies for IF (1:1000, Molecular Probes) were incubated for $45 \mathrm{~min}$ followed by mounting with DAPI Vectashield.

Tissue recombination. Tissue recombination was performed as described previously. ${ }^{17}$ Briefly, $400 \mathrm{~K}$ of each mPrE-PPAR $\gamma \mathrm{KO}$-related cell lines were recombined with 18-day fetal rat UGM and grafted in collagen into the kidney 
capsule of male SCID mice for 2 months. Grafts were harvested and fixed in formalin for morphologic and immunohistochemical analysis.

Glucose/lactate measurements. Extracellular uptake and excretion rates were determined in triplicate growth experiments. Eight separate 48-well tissue culture plates were seeded at a density of $20 \mathrm{~K}$ cells. One plate was sampled every $10-14 \mathrm{~h}$, whereby the conditioned medium was removed and frozen at $-80^{\circ} \mathrm{C}$. The remaining cells on the plate were stained with crystal violet for assessment of cell number. Concentrations of medium glucose and lactate were determined using a YSI 2300 Stat Plus Glucose and Lactate Analyzer (YSI, Yellow Springs, $\mathrm{OH}$, USA). Cell-specific rates of glucose consumption and lactate production were determined by regression analysis using the method of Glacken et al. ${ }^{40}$

Animal experiments. To examine the effects of TZD or HFD regimen on prostate gene expression in vivo, control, Rosiglitazone chow $(0.188 \%$ Avandia) or Western diet chow (16\% protein, $40 \%$ carbohydrate, $40 \%$ fat, $0.15 \%$ cholesterol) (Test Diets, Richmond, IN, USA) were fed to male C57B mice for 6 months at which time the animals were weighed (Student's unpaired $t$ test for statistical analysis) and tissues removed for formalin fixation and storage at $-80^{\circ} \mathrm{C}$ for later RNA extraction. Because of the extreme density of adipose directly surrounding the prostate of both TZD- and HFD-fed animals, care was taken to dissect away as much as possible. WAT was taken from the epididymal fat pad. RNA was extracted and CDNA synthesized for qRT-PCR on custom-designed plates (Qiagen) using an $\mathrm{ABI} 7900 \mathrm{HT}$ real-time PCR machine with a standard block according to the manufacturer's instructions. Results represent triplicate experiments and fold changes were calculated as described above. $P$ values were mostly insignificant, given the contamination by intramuscular adipocytes and were therefore not shown.

\section{Conflict of Interest}

The authors declare no conflict of interest.

Acknowledgements. All microarray experiments were performed in the Vanderbilt Genome Sciences Resource. The Vanderbilt Genome Sciences Resource is supported by the Vanderbilt Ingram Cancer Center (P30 CA68485), the Vanderbilt Digestive Disease Center (P30 DK58404) and the Vanderbilt Vision Center (P30 EY08126). This work was supported by a Department of Defense Prostate Cancer Training Award W81XWH-07-1-0479 to DWS, P20 DK090874 and 2R01 DK067049 to SWH, and R21 CA155964 to JDY. All fatty acid analyses were performed by the Vanderbilt Hormone Assay and Analytical Services Core. We thank Drs. Robert Matusik and David Degraff for helpful discussions and manuscript editing.

1. Hammarsten J, Peeker R. Urological aspects of the metabolic syndrome. Nat Rev Urol 2011; 8: 483-494.

2. Bourke JB, Griffin JP. Diabetes mellitus in patients with benign prostatic hyperplasia. Br Med J 1968; 4: 492-493.

3. Parsons JK, Carter HB, Partin AW, Windham BG, Metter EJ, Ferrucci L et al. Metabolic factors associated with benign prostatic hyperplasia. J Clin Endocrinol Metab 2006; 91 : 2562-2568.

4. Berger AP, Bartsch G, Deibl M, Alber H, Pachinger O, Fritsche G et al. Atherosclerosis as a risk factor for benign prostatic hyperplasia. BJU Int 2006; 98: 1038-1042.

5. Burke JP, Rhodes T, Jacobson DJ, McGree ME, Roberts RO, Girman CJ et al. Association of anthropometric measures with the presence and progression of benign prostatic hyperplasia. Am J Epidemiol 2006; 164: 41-46.

6. Michel MC, Mehlburger L, Schumacher H, Bressel HU, Goepel M. Effect of diabetes on lower urinary tract symptoms in patients with benign prostatic hyperplasia. J Urol 2000; 163: $1725-1729$.

7. Freeman MR, Solomon KR. Cholesterol and benign prostate disease. Diff Res Biol Div 2011; 82: 244-252.

8. Yeh HC, Platz EA, Wang NY, Visvanathan K, Helzlsouer KJ, Brancati FL. A prospective study of the associations between treated diabetes and cancer outcomes. Diab Care 2012; 35: 113-118.

9. Grundmark B, Garmo H, Loda M, Busch C, Holmberg L, Zethelius B. The metabolic syndrome and the risk of prostate cancer under competing risks of death from other causes. Cancer Epidemiol Biomarkers Prev 2010; 19: 2088-2096.

10. Flavin R, Zadra G, Loda M. Metabolic alterations and targeted therapies in prostate cancer. J Pathol 2011; 223: 283-294.
11. Lee $\mathrm{CH}$, Olson $\mathrm{P}$, Evans RM. Minireview: lipid metabolism, metabolic diseases, and peroxisome proliferator-activated receptors. Endocrinology 2003; 144: 2201-2207.

12. Cheatham WW. Peroxisome proliferator-activated receptor translational research and clinical experience. Am J Clin Nutr 2010; 91: 262S-266S.

13. Hsiao G, Chapman J, Ofrecio JM, Wilkes J, Resnik JL, Thapar D et al. Multi-tissue, selective PPARgamma modulation of insulin sensitivity and metabolic pathways in obese rats. Am J Physiol Endocrinol Metab 2011; 300: E164-E174.

14. He W, Barak Y, Hevener A, Olson P, Liao D, Le J et al. Adipose-specific peroxisome proliferator-activated receptor gamma knockout causes insulin resistance in fat and liver but not in muscle. Proc Natl Acad Sci USA 2003; 100: 15712-15717.

15. Vidal-Puig A, Jimenez-Linan M, Lowell BB, Hamann A, Hu E, Spiegelman B et al. Regulation of PPAR gamma gene expression by nutrition and obesity in rodents. J Clin Invest 1996; 97: 2553-2561.

16. Norris AW, Chen L, Fisher SJ, Szanto I, Ristow M, Jozsi AC et al. Muscle-specific PPARgamma-deficient mice develop increased adiposity and insulin resistance but respond to thiazolidinediones. J Clin Invest 2003; 112: 608-618.

17. Jiang M, Fernandez S, Jerome WG, He Y, Yu X, Cai $\mathrm{H}$ et al. Disruption of PPARgamma signaling results in mouse prostatic intraepithelial neoplasia involving active autophagy. Cell Death Differ 2010; 17: 469-481.

18. Jiang M, Jerome WG, Hayward SW. Autophagy in nuclear receptor PPARgamma-deficient mouse prostatic carcinogenesis. Autophagy 2010; 6: 175-176.

19. Jiang M, Strand DW, Franco OE, Clark PE, Hayward SW. PPARgamma: A molecular link between systemic metabolic disease and benign prostate hyperplasia. Differentiation 2011; 82: 220-236.

20. Fajas L, Auboeuf D, Raspe E, Schoonjans K, Lefebvre AM, Saladin R et al. The organization, promoter analysis, and expression of the human PPARgamma gene. J Biol Chem 1997; 272: 18779-18789.

21. Clarke SD. Polyunsaturated fatty acid regulation of gene transcription: a molecular mechanism to improve the metabolic syndrome. J Nutr 2001; 131: 1129-1132.

22. Sampath $\mathrm{H}, \mathrm{Ntambi} \mathrm{JM}$. The role of stearoyl-CoA desaturase in obesity, insulin resistance, and inflammation. Ann N Y Acad Sci 2011; 1243: 47-53.

23. Miyazaki M, Sampath H, Liu X, Flowers MT, Chu K, Dobrzyn A et al. Stearoyl-CoA desaturase-1 deficiency attenuates obesity and insulin resistance in leptin-resistant obese mice. Biochem Biophys Res Commun 2009; 380: 818-822.

24. Kelley DE. Skeletal muscle fat oxidation: timing and flexibility are everything. J Clin Invest 2005; 115: 1699-1702

25. Sears DD, Hsiao G, Hsiao A, Yu JG, Courtney CH, Ofrecio JM et al. Mechanisms of human insulin resistance and thiazolidinedione-mediated insulin sensitization. Proc Natl Acad Sci USA 2009; 106: 18745-18750.

26. Medina-Gomez G, Gray SL, Yetukuri L, Shimomura K, Virtue S, Campbell M et al. PPAR gamma 2 prevents lipotoxicity by controlling adipose tissue expandability and peripheral lipid metabolism. PLoS Genet 2007; 3: e64.

27. Walden TB, Hansen IR, Timmons JA, Cannon B, Nedergaard J. Recruited vs. nonrecruited molecular signatures of brown, "brite," and white adipose tissues. Am J Physiol Endocrinol Metab 2012; 302: E19-E31.

28. Kelly LJ, Vicario PP, Thompson GM, Candelore MR, Doebber TW, Ventre J et al. Peroxisome proliferator-activated receptors gamma and alpha mediate in vivo regulation of uncoupling protein (UCP-1, UCP-2, UCP-3) gene expression. Endocrinology 1998; 139: 4920-4927.

29. Danaei G, Finucane MM, Lu Y, Singh GM, Cowan MJ, Paciorek CJ et al. National, regional, and global trends in fasting plasma glucose and diabetes prevalence since 1980: systematic analysis of health examination surveys and epidemiological studies with 370 country-years and 2.7 million participants. Lancet 2011; 378(9785): 31-40.

30. Chavez JA, Summers SA. Lipid oversupply, selective insulin resistance, and lipotoxicity: molecular mechanisms. Biochim Biophys Acta. 2010; 1801: 252-265.

31. De Nunzio C, Aronson W, Freedland SJ, Giovannucci E, Parsons JK. The correlation between metabolic syndrome and prostatic diseases. Eur Urol 2012; 61: 560-570.

32. Strand DW, Franco OE, Basanta D, Anderson AR, Hayward SW. Perspectives on tissue interactions in development and disease. Curr Mol Med 2010; 10: 95-112.

33. Way JM, Harrington WW, Brown KK, Gottschalk WK, Sundseth SS, Mansfield TA et al. Comprehensive messenger ribonucleic acid profiling reveals that peroxisome proliferatoractivated receptor gamma activation has coordinate effects on gene expression in multiple insulin-sensitive tissues. Endocrinology 2001; 142: 1269-1277.

34. Moore S, Knudsen B, True LD, Hawley S, Etzioni R, Wade C et al. Loss of stearoyl-CoA desaturase expression is a frequent event in prostate carcinoma. Int $J$ cancer 2005; 114: 563-571.

35. Fritz V, Benfodda Z, Rodier G, Henriquet C, Iborra F, Avances C et al. Abrogation of de novo lipogenesis by stearoyl-CoA desaturase 1 inhibition interferes with oncogenic signaling and blocks prostate cancer progression in mice. Mol Cancer Ther 2010; 9: 1740-1754.

36. Vikram A, Jena G, Ramarao P. Pioglitazone attenuates prostatic enlargement in dietinduced insulin-resistant rats by altering lipid distribution and hyperinsulinaemia. Br J Pharmacol 2010; 161: 1708-1721.

37. Vikram A, Jena GB, Ramarao P. Increased cell proliferation and contractility of prostate in insulin resistant rats: linking hyperinsulinemia with benign prostate hyperplasia. Prostate 2010; 70: 79-89.

38. Rikimaru $\mathrm{K}$, Wakabayashi $\mathrm{T}$, Abe $\mathrm{H}$, Imoto $\mathrm{H}$, Maekawa $\mathrm{T}$, Ujikawa $\mathrm{O}$ et al. A new class of non-thiazolidinedione, non-carboxylic-acid-based higshly selective peroxisome 
proliferator-activated receptor (PPAR) gamma agonists: design and synthesis of benzylpyrazole acylsulfonamides. Bioorg Med Chem 2012; 20: 714-733.

39. Folch J, Lees M, Sloane Stanley GH. A simple method for the isolation and purification of total lipides from animal tissues. J Biol Chem 1957; 226: 497-509.

40. Glacken MW, Adema E, Sinskey AJ. Mathematical descriptions of hybridoma culture kinetics: I. Initial metabolic rates. Biotechnol Bioeng 1988; 32: 491-506.
Cell Death and Disease is an open-access journal SOMEREAHISRESERVED published by Nature Publishing Group. This work is
licensed under the Creative Commons Attribution-NonCommercial-No Derivative Works 3.0 Unported License. To view a copy of this license, visit http://creativecommons.org/licenses/by-nc-nd/3.0/

Supplementary Information accompanies the paper on Cell Death and Disease website (http://www.nature.com/cddis) 